\title{
Conhecimento científico e tecnológico dos povos africanos: estratégia de resistência à tradição seletiva no ensino de ciências
}

Marlene Oliveira de Brito*

Vitor Machado**

*(Universidade Estadual Paulista Júlio de Mesquita Filho - Unesp, Bauru, SP, Brasil)

**(Universidade Estadual Paulista Júlio de Mesquita Filho - Unesp, Bauru, SP, Brasil)
Resumo: 0 presente artigo examina possibilidades de inclusão da história e culturas africanas e afro-brasileiras no ensino de ciências, em atendimento à Lei 10.639/03, defendendo a inserção da diversidade étnico-racial e cultural a partir do recorte histórico referente ao conhecimento científico de povos africanos. A análise é realizada nos conteúdos propostos no currículo escolar oficial da Secretaria de Educação do Estado de São Paulo (SEE/SP), especificamente para $07^{0}$ ano do ensino fundamental. A proposta é refletir sobre a atuação pedagógica dos envolvidos na educação escolar, como instrumento capaz de resultar em significações no posicionamento diante as demandas relativas ao enfrentamento do preconceito e da discriminação com fundamento racial.

Palavras-chave: Educação antirracista. Ciência e tecnologia africana. Currículo e ensino de ciências. 


\section{INTRODUÇÃO}

Sabemos que o período de escravização no Brasil foi marcado por um intenso processo de construção de estereótipos e estigmas que tentavam diluir a dignidade dos afro-brasileiros. Seus efeitos permanecem entranhados em nossa sociedade, haja vista a naturalidade com que são encaradas as imagens que posicionam o negro em condição de subalternidade. A ausência de referências positivas no conteúdo programático escolar e a negação da contribuição dos povos africanos na produção do conhecimento, ciência e tecnologia reforçaram a mentalidade em torno da inferioridade dos povos africanos e seus descendentes.

Quando analisamos o cenário educacional brasileiro notamos que a figura do negro e suas realizações, nas mais diversas áreas de conhecimento e atividade humana, ficaram alijadas do currículo escolar. Sobre essa ausência paira, no interior das escolas, o silêncio perpétuo. Conforme afirma Nascimento (2003, p. 22), "o silêncio configura uma das formas mais eficazes de operação do racismo no Brasil”.

A natureza pluricultural da nossa sociedade exige que as escolas incluam indivíduos vindos de processos e grupos socialmente excluídos pelas desigualdades. 0 equacionamento das questões que essa realidade impõe à prática docente pede mais que a presença física, exigindo posicionamento político e compromisso ético. Além disso, exige também articulações na criação de espaços de resistência à "tradição seletiva", entendida aqui, a partir das considerações de Apple (2001), como a ausência da herança histórico-cultural de determinados segmentos significativos da população, como parte do conteúdo que constitui os materiais curriculares mais utilizados pelas escolas.

O contexto escolar pode configurar-se em ambiente privilegiado na promoção de debates e reflexões acerca da dinâmica das relações sociais em uma sociedade multicultural e pluriétnica. Sendo assim, torna-se urgente a necessidade de inclusão de conteúdos que tenham a diversidade étnicoracial e cultural como princípio de ensino em todas as áreas de conhecimento.

1 Entende-se por "tradição seletiva", a partir das considerações de Apple (2001) retomando Raymond Williams (1978) e referindo-se ao movimento operário nos Estados Unidos, a ausência nos materiais curriculares mais utilizados da herança histórica de um determinado segmento significativo da população. No contexto desse artigo, a expressão é tomada em apropriação ao se referir à ausência das histórias e culturas dos povos negros africanos, afro-brasileiros e indígenas no currículo oficial do estado de São Paulo. 
No presente texto tratamos da inserção da temática da diversidade étnicoracial e cultural no ensino fundamental, a partir da análise do conteúdo da disciplina de ciências, proposto pela Secretaria da Educação do Estado de São Paulo (SEE/SP), para o $7^{0}$ ano do ensino fundamental. Nossa intenção é propor reflexões que reconheçam a atividade pedagógica dos envolvidos na educação escolar como instrumento capaz de resultar em significações no posicionamento diante das demandas relativas ao enfrentamento do preconceito e da discriminação com fundamento racial.

\section{O CONHECIMENTO NEGADO COMO ESTRATÉGIA DE DOMINAÇÃO E IMPOSIÇÃO DA INFERIORIDADE}

O tema das relações étnico-raciais é um debate presente na sociedade brasileira. Assim, o processo educacional, desde os anos iniciais, pode contribuir formando pessoas em um contexto que necessita de reformulações de padrões ideológicos. A educação pública básica tem sido o lugar de formação escolar da maioria das crianças e dos jovens negros. Dessa forma, ela precisa estar atenta para a abordagem das demandas sociais, uma vez que sua tarefa é lidar com a formação de pessoas em meio à multiplicidade social, cultural e étnico-racial. No entanto, na configuração curricular, nas práticas pedagógicas, nos discursos e nas narrativas que se constroem no universo escolar a figura do negro, tal como a do indígena, da mulher e dos trabalhadores, são "signos" ausentes.

A estratégia de inclusão da temática étnico-racial no currículo escolar, a partir da contribuição de povos africanos nas áreas de conhecimento científico, tem relação com a ausência dessa narrativa no contexto escolar. Evidenciar positivamente referências ancestrais da história da África relaciona-se ao fato de o estudante afro-brasileiro passar a conhecer a história de seus antepassados, não apenas no contexto exclusivo da escravização. O que tende a contribuir com uma formação que fortalece sua autoestima, a noção de pertença e autoaceitação. Nesse sentido, a educação escolar the ofereceria condições de romper com o silêncio imposto simbolicamente, criando possibilidades de almejar e efetivar a participação nos espaços em que ainda não se faz presente. Do mesmo modo, também participaria da formação da criança e do jovem não negro à medida que criaria possibilidades de valorização e de reconhecimento do outro.

Autores como Fanon (2008), Taylor (1993) e Nascimento (2003) sugerem que o processo de construção de identidades, tanto individuais como coletivas, 
está vinculado à necessidade de se reconhecer o outro. É no contexto escolar que surge a possibilidade, por meio da implantação de políticas públicas, de se garantir minimamente o reconhecimento das diferenças existentes entre os indivíduos e os grupos culturais que ainda carecem de visibilidade.

Podemos dizer que a faceta mais cruel da colonização foi a redefinição dos padrões culturais a um único paradigma. Ela teve como pano de fundo a dissolução dos conhecimentos produzidos por outros povos, além da descontextualização dos saberes da cultura popular e suas formas de transmissão. Essa hierarquização entre saberes e conhecimentos mantém-se intacta nesse processo, que resulta de uma história de dominação, exploração e colonialismo.

Para os autores do grupo Modernidade/Colonialidade ${ }^{2}$ as relações que se estabeleceram entre colonizadores e colonizados foram muito além das imposições políticas, econômicas e administrativas, uma vez que se mantiveram após a emancipação jurídico-política das colônias e adquiriram permanência com o padrão de poder que emergiu do colonialismo: a colonialidade. As estruturas subjetivas, o imaginário e a colonização epistemológica ainda estão fortemente presentes.

Todo um complexo legado cultural e histórico é diluído em um conjunto de formas e padrões dominantes de valores. Nesses termos, a colonialidade impõe novas formas de produção de conhecimento. Atua, inclusive, na construção da subjetividade dos indivíduos e na autoimagem que os povos colonizados têm de si e de sua cultura, uma vez que passam a ser seduzidos e formatados pelos valores e padrões eurocêntricos.

A dissolução dos conhecimentos, das cosmovisões, das realizações intelectuais, materiais e simbólicas, produzidos por outros povos, é parte da mentalidade de longa duração que inferiorizou grupos humanos com vistas à manutenção de uma organização social hierarquizada. "A colonialidade é um dos elementos constitutivos e específicos do padrão mundial do poder

Grupo de pesquisa formado, em sua maioria, por intelectuais da América Latina que propõe a construção de um projeto epistemológico, ético e político a partir da crítica à modernidade ocidental eurocêntrica, em seus postulados históricos, sociológicos e filosóficos. A colonialidade do poder, do saber e do ser são conceitos centrais dentro do projeto de investigação. Seus principais expoentes são: o filósofo argentino Enrique Dussel, o sociólogo peruano Aníbal Quijano, o semiólogo e teórico cultural argentinonorte-americano Walter Mignolo, o sociólogo porto-riquenho Ramón Grosfoguel, a linguista norte-americana radicada no Equador Catherine Walsh, o filósofo portoriquenho Nelson Maldonado Torres e o antropólogo colombiano Arturo Escobar. 
capitalista. Se funda na imposição de uma classificação racial/étnica da população mundial como pedra angular deste padrão de poder" (QUIJANO, 2005, p. 93).

Os estudos do grupo Modernidade/Colonialidade têm produzido reflexões teóricas interdisciplinares que pretendem desconstruir a naturalização da epistemologia ocidental. Propõem formas de reconhecer outros conhecimentos com um olhar sobre as subjetividades excluídas. Nesse contexto, as orientações das diretrizes curriculares nacionais para a educação das relações étnico-raciais (BRASIL, 2004) mantêm estreiteza com as reflexões sobre a colonialidade, abrindo possibilidades para novas formulações teóricas e práticas no ensino brasileiro. Para Moore (2007), as diretrizes Curriculares Nacionais estabelecem algumas determinações de conteúdo no ensino de história que mobilizam uma reorientação epistemológica de interpretação da história.

A questão que se coloca, no entanto, diz respeito à incorporação dessa mudança de paradigma no cotidiano das escolas, ou antes, nos próprios cursos de licenciatura e de formação inicial de professores, a ponto de produzir redirecionamento de atitudes e resistência perante os currículos oficiais que ignoram, inclusive, os preceitos legais.

A estrutura ideológica própria do colonialismo incorporou a heterogeneidade das histórias e culturas ao universo europeu, criando uma única configuração cultural, intelectual e de produção do conhecimento a ser reconhecida e valorizada. O currículo materializado nas escolas continua centrado em uma visão eurocêntrica de mundo, reduzindo a diversidade cultural e epistemológica ao universo europeu, preservado pela organização seletiva de conteúdos. Para Apple (2001, p. 90), as escolas são agentes no processo de criação e recriação de uma cultura predominante eficaz, ensinando

[...] normas, valores, ensinamentos e uma determinada cultura, que contribuem para a hegemonia ideológica dos grupos dominantes. [...]". Assim, actuam como agentes daquilo que Raymond Williams denominou por "tradição selectiva".

Romper com a "tradição seletiva" exige do contexto escolar a reunião de esforços, a fim de criar possibilidades para que os indivíduos se encontrem com outros nos espaços que habitam. Tais encontros podem permitir a reflexão, a percepção do outro e o reconhecimento das diferenças em um contexto de múltiplas relações. O fato é que, conforme afirma Moore (2005, p. 158), 


\section{[...] o novo empreendimento docente preconizado na Lei 10.639/03 não poderá prescindir da historiografia especificamente produzida por africanos, sem ferir gravemente as exigências de rigor e de respeito pela verdade cientificamente elaborada e demonstrada.}

Além desse compromisso com a verdade científica, a atuação docente exige a compreensão de que os processos de produção do conhecimento e formação envolvem a construção de representações sobre as populações indígenas e negras, urbanas e rurais. É no contexto das relações de poder que podemos contribuir tanto com práticas emancipatórias quanto com a manutenção de papéis sociais estabelecidos no contexto da colonialidade.

\section{O SILÊNCIO DOS DOCENTES E A AUSÊNCIA DO SIGNO NEGRO NA ESCOLA}

Como pontua Candau (2011) diferentes grupos socioculturais conquistaram maior presença nos cenários públicos em nosso país, "reivindicando igualdade de acesso a bens e serviços e reconhecimento político e cultural" (CANDAU 2011, p. 241). Esse cenário tem imposto certos desafios ao sistema educacional e à prática pedagógica dos envolvidos nos processos de formação de crianças e jovens no Brasil. Os maiores deles, talvez, sejam o acolhimento das diferenças e a revisão de padrões ideológicos que não problematizam a manutenção de um currículo eurocêntrico ${ }^{3}$, desconsiderando a diversidade dos povos constituidores da sociedade brasileira.

De acordo com Silva e Brandin (2008), podemos considerar entre um dos fundamentos do multiculturalismo ${ }^{4}$ a capacidade de levar em conta a pluralidade cultural no âmbito da educação, pensando formas de reconhecer, valorizar e incorporaras identidades plurais em políticas e práticas curriculares.

Nessas condições, atendendo a antigas reivindicações das diversas entidades do Movimento Negro Brasileiro, em 2003, o Ministério da Educação sancionou a Lei 10.639/03 (BRASIL, 2003), instituindo a obrigatoriedade do ensino da Cultura e da História Africanas e Afro-brasileiras, em todas as disciplinas do Ensino Fundamental e Médio, sobretudo nas de História, de

3 A utilização do termo "eurocêntrico" relaciona-se com o que pontua Nascimento (1994) ao destacar que o eurocentrismo faz uso de falsificação histórica e violência para imporse como referencial universal à humanidade, sustentado pela ideologia da suposta superioridade física, econômica, religiosa e social dos grupos étnicos europeus perante os outros grupos étnicos.

4 A noção de multiculturalismo deve ser entendida do modo proposto por Hall (2003, p. 52), em que o “termo ‘multiculturalismo' refere-se às estratégias e políticas adotadas para governar ou administrar problemas de diversidade e multiplicidade gerados pelas sociedades multiculturais". 
Literatura e de Artes. Além da inclusão no currículo oficial, a Lei prescreve uma nova abordagem dos temas africanos e dos afrodescendentes brasileiros no contexto educacional. A proposta visa tirar o foco da história dos povos africanos apenas no contexto da escravização e inserir a contribuição deles e de seus descendentes para a ciência, no que tange ao desenvolvimento de tecnologia e à produção do conhecimento na literatura, na arte e na cultura. Isso significa garantir a problematização das relações étnico-raciais na sociedade brasileira em uma perspectiva histórica.

Todavia, as razões da inserção no currículo escolar, da diversidade étnicoracial e cultural, vão além do reconhecimento das diferenças, uma vez que se relacionam, conforme aponta Taylor (1993), com dimensões fundamentais da construção de identidades culturais. Para Souza (2009), inserir no currículo da escola a história, a cultura, as contribuições e a luta dos negros oriundos da diáspora africana tende a dar visibilidade às lutas do movimento negro, às políticas públicas de ação afirmativa e à desconstituição do mito da democracia racial no espaço educativo. Esse procedimento proporciona uma nova dimensão de interpretação e valorização da identidade cultural de povos historicamente marginalizados.

Tais formulações assumem importância fundamental se considerarmos que, no contexto escolar atual, a tendência ainda é contribuir com a reprodução da discriminação e do preconceito, na medida em que as minorias étnicas não se veem inseridas na escola. Portanto, não se formam identitariamente, tendo em vista que não encontram referências positivas da sua origem, da sua cultura e da sua história no processo de escolarização. De acordo com Nascimento (2003), a questão da identidade está estruturalmente ligada à essência da dominação racista, levando em consideração os efeitos que mecanismos ideológicos exercem sobre o negro em relação ao "ideal de ego branco" historicamente imposto.

As representações sociais, como construções históricas, dão sustentação às imagens negativas ou positivas em relação aos diferentes grupos étnicos e sociais. No caso da população negra, essas representações se materializam em atos cotidianos, conscientes ou não, que determinam o lugar que o negro “deve" ocupar na hierarquia social. 0 modo velado de operação do racismo no contexto brasileiro é um dos mecanismos responsáveis pela incapacidade das instituições de perceber suas evidências e atuar em seu combate (SEGATO, 2005).

É no espaço escolar que a dinâmica das relações étnico-raciais no ensino 
precisa ser revisitada, debatida e devidamente contextualizada. Isso possibilita que não se perpetuem a indiferença e o racismo institucional, naturalizados também na completa ausência dos negros no currículo escolar. Nesse sentido, a Lei 10.639/03 (BRASIL, 2003) é uma resposta à necessidade de levar à comunidade escolar o passado histórico e o presente dos povos africanos e seus descendentes. A ausência dessas histórias e culturas do currículo contribui com os mecanismos ideológicos de estigmatização da população africana e afro-brasileira.

\section{O LEGADO NEGADO NA ESCOLA: O CONHECIMENTO CIENTÍFICO E TECNOLÓGICO DOS POVOS AFRICANOS}

O estudo de pesquisadores sobre a diversidade das culturas africanas trouxe à tona "um passado que está na história, mas não na escola" (FONSECA, 2012, p. 95). Essa omissão no processo educacional, além de configurar uma posição política, revela também uma história construída, intencionalmente, com o intuito de suprimir as contribuições de inúmeras culturas africanas nas mais diversas áreas de atividade humana.

Uma das principais perversidades realizadas pelo eurocentrismo foi a negação do passado científico e tecnológico dos povos africanos, de modo a constituir uma mentalidade de longa duração que não reconhece as contribuições dessa população para a construção do conhecimento universal.

Oolharinconformado econtestadordehistoriadores, cientistase pesquisadores de vários países deve muito aos que ousaram desafiar os meios acadêmicos “eurocêntricos”, tais como: James (1992), Diop (1954, 1967), Ki-Zerbo (1972), Obenga (2001), Asante (1980), Van Sertima (1983), Nascimento (1994) e outros. Na visão desses pesquisadores, a África deve ser compreendida como o lugar das primeiras descobertas, invenções e instituições humanas. Eles têm apontado evidências que demonstram a existência da primeira revolução tecnológica da humanidade no continente africano. É importante destacar que diferentes autores apresentaram críticas a essa abordagem, dentre os quais se destacam Lefkowitz (1997), Howe (1998), Adeleke (2009) e Walker (2001). No entanto, entendemos que suas críticas situam-se na operação do conhecimento na chave do pensamento eurocêntrico. Daí a necessidade de aprofundarmos o debate em torno das reflexões sugeridas neste texto.

De acordo com Fonseca (2012) diversos estudos apontam indícios de que o saque e a destruição da biblioteca de Alexandria, no Egito, encobriram 
um processo contínuo de apagamento e de descrédito dos conhecimentos africanos, tornando-os exóticos, místicos e míticos. Para James ${ }^{5}$ (1992), no texto intitulado "O legado roubado" (Stolen Legacy), na filosofia grega, Alexandre - "o Grande” - rei da Macedônia (338 a.C. - 323 a.C.), desempenhou papel fundamental no processo de apagamento da origem africana desse conhecimento quando invadiu o Egito em 333 a.C., saqueando e pilhando a Biblioteca Real de Alexandria, levando um espólio de livros científicos, filosóficos e religiosos. Ainda segundo James (1992) os gregos roubaram o legado do continente africano, tomando-o para si. Uma das consequências dessa desonestidade foi a criação de uma opinião mundial errônea, de que o continente africano não produziu nenhuma contribuição para a civilização.

Farrington (1961), historiador irlandês do século XX, que se dedicou ao estudo do desenvolvimento do pensamento científico na cultura ocidental, tratou em sua obra da dívida grega às mais antigas civilizações, ao desconsiderar os conhecimentos práticos dos povos antigos do Oriente, formadores das bases e da fundamentação para o pensamento científico grego.

Não devemos, tampouco, esquecer a medicina e a cirurgia dos egípcios, tal como está revelada nos trabalhos de Edwin Smith, nem o calendário egípcio que foi considerado o único calendário inteligente na história humana, nem o sistema de pesos e medidas, o qual foi altamente desenvolvido, ambos em uso entre os egípcios e babilônios. Em resumo, ainda que os métodos de transmissão requeiram ulterior elucidação, estamos de acordo com os conhecimentos atuais, quando dizemos que os gregos devem às mais antigas civilizações não somente as técnicas, mas também considerável conjunto de conhecimentos científicos (FARRINGTON, 1961, p. 11).

Ao relatar a produção de conhecimento de origem africana, Machado (2014) destaca uma declaração do político, historiador e filósofo francês Conde Constantine François de Volney (1757-1820), constatando as evidências africanas no Egito antigo:

\footnotetext{
O dr. George Granville Monah James nasceu em Georgetown, Guiana, América do Sul. James alcançou os graus de bacharel em Artes, bacharel em Teologia e mestrado em Artes pela Universidade de Durham, na Inglaterra. Conduziu pesquisas na Universidade de Londres e fez trabalho de pós-graduação na Universidade de Columbia, onde se titulou Ph.D. 0 dr. James foi o autor do amplamente divulgado 0 legado roubado: os gregos não foram os autores da filosofia grega, mas as pessoas do Norte de África, comumente chamados de egípcios - um texto polêmico, originalmente publicado em 1954 e reeditado várias vezes desde então. A trágica morte do dr. James, sob circunstâncias misteriosas, supostamente veio logo após a publicação de 0 legado roubado.
} 
Lembrei-me da notável passagem onde diz Heródoto: "E quanto a mim, julgo serem os colchianos uma colônia dos egípcios porque, iguais a estes, são negros de cabelo lanudo”. Em outras palavras, os antigos egípcios antigos eram verdadeiros negros, do mesmo tipo que todos os nativos africanos. [...] Basta pensar que essa raça de homens negros, hoje nossos escravos e objeto de nosso desprezo, é a mesma raça à qual devemos nossas artes, ciências e até mesmo o uso do discurso! Imaginem que estamos no meio de pessoas que se dizem os maiores amigos da liberdade e da humanidade e que aprovaram a escravidão mais bárbara e questionando se os homens negros têm o mesmo tipo de inteligência que os brancos

Nessa mesma direção James (1992, p. 13) apresenta extensos argumentos e evidências que questionam, de forma contundente, a origem da chamada filosofia Grega, afirmando que “[...] Ambas as pessoas brancas e pretas são vítimas comuns de uma falsa tradição sobre a África, e este fato faz de ambas as raças parceiros na solução do problema da reforma racial".

Pesquisadores brasileiros, entre eles Nascimento (1996), Fonseca (2012) e Machado (2014) reúnem em várias de suas produções uma série de provas da contribuição de povos africanos nas diversas áreas de atividade humana.

De acordo com Machado (2014), o ser humano moderno criou ferramentas de ossos e lâminas por volta de 90.000 a 60.000 a.C., na África Austral e África Oriental. 0 uso de ferramentas de osso e lâmina tornou-se característica para a indústria de ferramentas de pedra mais tarde. Em suas pesquisas, o autor afirma também que grupos humanos do sul da África já se valiam de ferramentas complexas e objetos dotados de carga simbólica há pelo menos 75.000 anos. Artefatos de osso e de ocre da Idade da Pedra, achados na caverna Blombos, na África do Sul, são, até o momento, as mais antigas evidências de atividade matemática já encontrada.

Ainda conforme Machado (2014), o sistema de ensino do centro de aprendizagem de altos estudos Casa da Vida (Per Ankh) é considerado o segundo maior centro acadêmico e um dos primeiros receptáculos de sabedoria de que se tem conhecimento, surgido por volta de 3.100 a.C. no Egito, onde arquivos e escritos literários eram produzidos, ensinados e guardados. Entre os ensinamentos ministrados na Casa da Vida estavam os de medicina, astronomia, matemática, doutrina religiosa e línguas estrangeiras.

Souza e Mota (apud FONSECA, 2012, p. 97) nos informam também que diversos foram os povos africanos que lidaram com a metalurgia há milhares de anos. Citam ainda como exemplo o manuseio do metal desenvolvido pelos Haya ${ }^{6}$,

6 Haya: povo de fala banta habitante de uma região da Tanzânia. 
cerca de 2.000 anos atrás, em que "produziam aço em fornos que atingiam temperaturas mais altas em duzentos a quatrocentos graus centígrados do que eram capazes os fornos europeus até o séc. XIX”. Eles dizem ainda que

\begin{abstract}
A tecnologia aplicada na África antiga encontra-se nas ruínas de Monomatapa.?A Construção de Monomatapa, capital de um império que durou trezentos anos, significa uma verdadeira façanha de engenharia, encerrando uma cidade murada de dez mil habitantes. Coerente com a atitude eurocêntrica, os estudiosos atribuíram sua construção a povos exógenos à África, e até a extraterrestres, no vão esforço de negar que o Grande Zimbábue ${ }^{8}$ fosse construído por africanos negros (SOUZA; MOTTA apud FONSECA, 2012, p. 98).
\end{abstract}

No que tange ao Grande Zimbábue, após 30 anos de pesquisa, constatouse que ele pode ter sido um observatório astronômico, diz Richard Wade, pesquisador do Observatório Nkwe Ridge da África do Sul.

Machado (2014) também relata que os médicos egípcios eram renomados na África por suas habilidades curativas e alto grau de especialização, conforme observado pelo historiador grego Heródoto: havia médicos especializados em cabeça, estômago, olhos e dentistas. Entre eles, destaca-se Imhotep, considerado o primeiro arquiteto, engenheiro e médico da história antiga. Filho de Ptah viveu durante o Antigo Império Egípcio, entre os anos de 2.686 2613 a.C. e morreu 2.500 anos antes do nascimento de Hipócrates, conhecido atualmente como o pai da medicina. Atribui-se a Imhotep os primeiros tratados médicos escritos. A primeira médica conhecida da história é Merit Ptah, de 2700 a.C. Ela não era apenas uma médica, mas chefe de uma equipe.

De acordo com Nascimento (apud FONSECA, 2012), o conhecimento médico não esteve situado apenas no norte africano. Na região que hoje compreende Uganda, país da África Central, os Banyoro realizavam a cirurgia de cesariana antes do ano de 1879, quando o dr. R. W. Felkin, cirurgião inglês, conheceu essa técnica com extrema eficácia e técnica de assepsia, anestesia, hemostasia e cauterização. O saber médico cirúrgico antigo e tradicional na África também operava os olhos removendo as cataratas. Essa técnica foi encontrada no Mali e no Egito. Cerca de 4.600 anos atrás, neste último país mencionado, já se fazia a cirurgia para a retirada de tumores cerebrais. Os Banyoro detinham há séculos o conhecimento sobre a vacinação e a farmacologia. Logo, as técnicas médicas e terapêuticas africanas não estavam voltadas somente para o mundo mágico, mas ao conhecimento científico, para a observação atenta do paciente.

7 Monomatapa: antigo reino e hoje país Zimbábue.

8 O Grande Zimbábue é o que restou de um povoado construído por uma muralha monumental, centro de uma importante cultura dedicada à pecuária. Seus muros medem quase 10 metros de altura. 
Devemos lembrar ainda que a cidade de Timbuktu, Mali na África Ocidental, abrigou entre os séculos XII e XVI, três antigos centros de aprendizagem, Djinguereber, SidiYahya e Sankore formando a Universidade de Timbuktu, possivelmente a primeira do mundo. De acordo com informações do site da Unesco, Timbuktu era uma capital intelectual e espiritual e um centro para a propagação do Islã em toda a África nos séculos XV e XVI. Suas três grandes mesquitas, Djinguereber, Sankore e Sidi Yahya, lembram a era de ouro de Timbuktu. A Universidade de Sankore chegou a abrigar 25 mil alunos e teve uma das maiores bibliotecas do mundo, com cerca de 1 milhão de manuscritos. Timbuktu foi um importante centro de cópias de livros, reunião de grupos religiosos, produção científica e artística (MACHADO, 2014).

Os conhecimentos de astronomia egípcia datam de tempos remotos. 0 dispositivo astronômico conhecido mais antigo - um calendário que marca com precisão o solstício de verão - está localizado na bacia de Napta Playa, no Egito e data de 5.000 a.C., sendo mil anos mais velho que Stonehenge no Reino Unido. Os astrônomos do Egito antigo alinharam as pirâmides ao Polo Norte utilizando duas estrelas como referência: Mizar e Kochab na constelação de Ursa Maior. A descoberta foi feita por egiptólogos britânicos, que resolveram utilizá-las para confirmar com precisão quando as pirâmides foram construídas ${ }^{9}$. Concluíram que a construção das pirâmides de Gizé data de 2.480 a.C.

Os egípcios foram os primeiros a desenvolver o calendário de 365 dias e 12 meses, utilizado até os dias atuais, a partir da observação dos astros. No século XIV, Najmal-Din al-Misri escreveu um tratado descrevendo mais de cem tipos diferentes de instrumentos astronômicos e científicos, muitos dos quais inventados por ele. Foi com base na tradução de 14 manuscritos de Timbuktu, na Universidade de Sankore, que se desenvolveram os seguintes conhecimentos astronômicos: 1 . Uso do calendário Juliano; 2. Visão heliocêntrica do sistema solar; 3. Aplicação de cálculos matemáticos complexos para constituir diagramas de planetas e órbitas; 4. Desenvolvimento de algoritmos que orientava, precisamente, a posição de Timbuktu para Meca; 5. Registro de chuva de meteoros, evento astronômico ocorrido em agosto de 1583 (MACHADO, 2014).

Conforme aponta Nascimento (2007), outra descoberta impressionante é o saber astronômico dos africanos da nação Dogon ${ }^{10}$, de Mali, perto da antiga

9 Maiores informações divulgadas em 〈http://www.bbc.com/portuguese/ noticias/2000/001116_piramide.shtml. Acesso em: 12 jan. 2016.

10 De acordo com Fonseca (2012), um grande mistério cerca a vida dos Dogon - povo que 
capital universitária de Timbuktu. Nas palavras dessa cientista, com uma concepção moderna e um saber extremamente complexo do universo, os Dogon conheciam, cinco a sete séculos atrás, o sistema solar, a sua estrutura espiral da Via Láctea, as luas de Júpiter e os anéis de Saturno, além de saberem da natureza deserta e infecunda da lua, que diziam ser seca e morta, como sangue seco.

Machado (2014) ainda faz referência à Namoratunga como um sítio astronômico localizado no lado oeste do Lago Turkana ${ }^{11}$, no Quênia, datado de 300 a.C., aproximadamente. Namoratunga II contém 19 colunas de basalto, alinhadas com sete sistemas estelares: Triangulum, Plêiades, Bellatrix, Aldebaram, Orion central, Saiph e Sírius. Segundo o autor, Mark Lynch e Maatschap Robbins da Universidade Estadual de Michigan (EUA) descobriram o local em 1978, e Lynch defende que os pilares de basalto indicam as constelações ou estrelas para o calendário lunar de 12 meses e 354 dias para os Cuchitas ${ }^{12}$ do sul da Etiópia.

Apontamos aqui, brevemente, alguns exemplos das inúmeras e incontáveis contribuições que as culturas e as produções científicas africanas ofereceram a toda a civilização ocidental europeia ${ }^{13}$. São fatos ocultados por uma história construída, propositadamente, sob uma ideologia que inferioriza a África, os africanos e seus descendentes.

\section{Desafio à PRÁtica pedagógICA: POR um CURRÍCUlo QUE CONSIDERE O PRINCÍPIO DA DIVERSIDADE ÉTNICO-RACIAL ${ }^{14}$}

De acordo com Fonseca (2012), a inferiorização dos grupos humanos africanos e de seus descendentes teve início muito antes do período de escravização dessa população no Brasil. Esse processo contou ainda com o aval da ciência

se acredita ser de ascendência egípcia. Depois de saírem da Líbia, há milênios, fixaramse na falésia de Bandiagara, no Mali, África Ocidental, levando consigo as informações sobre o Cosmo, que remontam ao Egito pré-dinástico, anterior a 3.200 a.C.

11 Lago Turkana: é o maior lago salgado da África, localizado ao norte da República do Quênia. É um importante laboratório para o estudo de comunidades animais e vegetais.

12 Uma das primeiras civilizações a surgir no vale do rio Nilo. Os Estados cuchitas controlaram a região antes do período das incursões egípcias na área.

13 Pesquisadores apontam que a riqueza das realizações tecnológicas dos povos africanos é muito bem documentada na obra Black in Science: ancient and modern, de Van Sertima (1983).

14 A diversidade étnico-racial, alçada à condição de princípio de ensino com a entrada em vigor da Lei no 12.796/13, torna-se, nos dizeres de Costa Neto (2013), o instrumento filosófico-jurídico da desconstrução do racismo. 
e da Igreja Católica. A ciência ocidental teve papel fundamental na construção de uma mentalidade em torno da inferioridade do povo negro e de seus descendentes, pois "[...] muitos iluministas eram defensores da tese de que os "negros" faziam parte de uma "raça inferior", que estava ainda no primeiro estágio da evolução humana” (FONSECA, 2012, p. 100).

Ideologias historicamente construídas têm a função de criar e sustentar a base discriminatória dos indivíduos social e racialmente identificados como negros. No contexto brasileiro, transcorrido mais de um século desde a abolição da escravatura, as crianças e os adolescentes negros estão na escola, mas não se veem retratados nela. No processo educacional, a África, o africano e seus descendentes ainda aparecem no currículo escolar apenas na perspectiva da escravização, da história do sofrimento e da desgraça.

No caso específico do estado de São Paulo, desde 2008, portanto, após a promulgação da Lei 10.639/03, o governo estadual direciona o ensino por meio de "apostilas" 15 e orienta, por meio de documentos específicos, a prática pedagógica e a atuação dos professores das escolas públicas estaduais. Diante disso, fez-se necessário demonstrarmos como as prescrições legais têm sido abordadas nos materiais do currículo oficial paulista.

Ao realizar uma breve análise da proposta curricular elaborada pela Secretaria da Educação do Estado de São Paulo (SEE/SP) para o ensino de ciências do ensino fundamental - ciclo II (anos finais) observa-se, na apresentação do documento que recebe o nome de "Área de Ciências da Natureza e suas Tecnologias", a seguinte orientação:

A Proposta Curricular se completará com um conjunto de documentos dirigidos especialmente aos professores. São os Cadernos do Professor, organizados por bimestre e por disciplina. Neles, são apresentadas situações de aprendizagem para orientar o trabalho do professor no ensino dos conteúdos disciplinares específicos. Esses conteúdos, habilidades e competências são organizados por série e acompanhados de orientações para a gestão da sala de aula, para a avaliação e a recuperação, bem como de sugestões de métodos e estratégias de trabalho nas aulas, experimentações, projetos coletivos, atividades extraclasse e estudos interdisciplinares

(SÃO PAULO, 2008, p. 9, grifo nosso).

Conforme o excerto acima transcrito, a SEE/SP orienta que os cadernos direcionados aos professores e aos estudantes servem para conduzir a prática docente na sala de aula, desde a abordagem do tema, passando pela

15 Os cadernos de atividades das disciplinas, destinados aos estudantes das escolas públicas estaduais paulistas, são parte da proposta curricular do estado de São Paulo, que tem como referência o desenvolvimento de competências e habilidades e como objetivo, a unificação do currículo nas escolas públicas estaduais. 
metodologia a ser desenvolvida e chegando às atividades a serem realizadas pelos alunos. A proposta de se utilizar em toda a rede estadual um material pedagógico integralmente produzido pelo Programa São Paulo Faz Escola ${ }^{16}$ tem no âmbito da SEE/SP o seguinte objetivo:

Desenvolver competências e habilidades por meio da implantação de um material pedagógico unificado para os alunos e professores da rede estadual. O conteúdo é formulado por especialistas da Coordenadoria de Gestão da Educação Básica (CGEB), dentro das diretrizes do Currículo Oficial do Estado de São Paulo (SÃO PAULO, 2008).

Apesar de a Apresentação Geral da Proposta Curricular do Estado de São Paulo ter sido confeccionada por especialistas da educação básica, não encontramos nela nenhuma referência à Lei 10.639/03, tampouco nos cadernos de Ciências da Natureza e suas Tecnologias, dos anos finais do ensino fundamental ( $6^{\circ}$ ao 9 을. Em tais cadernos procuramos observar qual o tratamento dado à diversidade étnico-racial e cultural nos conteúdos abordados nas atividades propostas pelo currículo oficial.

Como a extensão deste texto não nos permite analisar os conteúdos de todas as séries do segmento optamos por um recorte para observação no ensino de ciências, do $6^{\circ}$ ano e do $7^{\circ}$ ano do ensino fundamental, a partir da temática do conhecimento astronômico de nações africanas, o qual poderia ser proposto como parte do conteúdo do tema "Terra e Universo" do currículo oficial.

Analisando os conteúdos estabelecidos pela SEE/SP para o ensino de ciências nos anos finais do ensino fundamental ( $6^{\circ}$ ao $9^{\circ}$ ano), que constam no “Material de apoio ao currículo do Estado de São Paulo - caderno do aluno - Ciências ensino fundamental - anos finais", encontramos no quadro de conteúdos do $6^{\circ}$ ano, no $4^{\circ}$ bimestre e no quadro de conteúdos do $7^{\circ}$ ano, no $1^{\underline{0}}$ bimestre, 0 tema "Terra e Universo". Tal tema está dividido em subtemas bimestrais, com descrição de conteúdos gerais e específicos. Um dos subtemas específicos apresentados nos quadros do currículo oficial a ser desenvolvido no 6 a ano intitula-se "Representações da Terra: lendas, mitos e crenças religiosas". No $7^{0}$ ano, o subtema é denominado "Cultura e Constelações”.

16 O programa São Paulo Faz Escola consiste em uma nova proposta curricular didáticopedagógica para o estado de São Paulo, elaborada e implementada pelo governo estadual paulista, por meio da Secretaria de Estado da Educação de São Paulo (SEE-SP), sob o comando da então secretária de Estado da Educação, Maria Helena Guimarães Castro, em 2008, no mandato do governador José Serra. O programa abarca os conteúdos curriculares e as expectativas de aprendizagem para os anos finais do ensino fundamental e para o ensino médio. 
Para saber se a diversidade étnico-racial é abordada no material oficial é precisamos analisar as atividades propostas nos "cadernos de atividades" dos alunos, também oferecidos pela SEE/SP. Nos "cadernos de atividades", os conteúdos destacados são tratados na sala de aula por meio de situações de aprendizagem, que podem ter uma ou mais aulas de duração, com encaminhamentos previamente definidos. Entre as atividades, podemos verificar uma variedade metodológica de abordagens que incluem: trabalho individual; trabalho em duplas ou trabalho coletivo, ilustrações, leituras de textos curtos, com certa variação nos gêneros, pesquisas breves, aplicação, experimentos e tarefas extraclasse.

No que se refere ao caderno de atividades de ciências do 6ำ ano, o conteúdo “Representações da Terra: lendas, mitos e crenças religiosas”, tratado na situação de aprendizagem 5, não apresenta qualquer atividade que faça referência aos conhecimentos produzidos por povos africanos. Observase o conteúdo dialogado exclusivamente com matrizes europeias, que não reconhece a diversidade de conhecimento existente, como podemos verificar em um dos textos para leitura, apresentado no caderno de atividade do aluno, conforme a Figura 1 a seguir:

Figura 1 - Texto referente à situação de aprendizagem 5

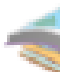

Leitura e andilise de texto

Leia o resto a seguir e reconsidere as ideias apresentadas anceriormente.

A esfericidade da Terra

A forma e a origem da Terra sempre inerigaram os seres humanos. Há relaros de concepcótes sobre nosso planeca e sobre o Universo que dacam de 3 ou 4 mil anos atrás, mas somente no século VT a.C. (há 2600 anos) iniciou-se uma investigapäo mais sistemática de faros que conduzissem a pereepsăo de que o nosso planeta 6 uma esfera. $\mathrm{B}$ somente no skeulo XVI, com a primeira viagem de circum-navegaça maríima (a primeira volea ao mundo), realizada pela equipe de Ferniso de Magalhises, essa ideia ganhou mais forca.

Para nós - que vivemos no século XXI, que crescemos vendo astonaucas, sondas espaciais e viagens à Lua, que testemunhamos a construçio de estaçós espaciais e até a viagem de um brasileiro a uma delas -, é fácil acreditat que habitamos uma esfera nochosa que orbita o Sol, nossa escrela. Mas, para nossos antepasados discantes, que viveram séculos ances de nós. imaginar a 'Terra como uma superficie esférica era considerado um simples aco de fe ou de excessiva criatividade.

Em termos históricos, Picágoras de Samos (572 a.C.-497 a.C.) foi uma das primeiras pessoas de que se cem noricia a afirmar a esfericidade da Terra, da Lua e de ourros corpos celestes. Ja Arisróreles de Eseagira (3a4 a.C.-322 a.C.), rambem partidário da esferieidade da Terra. foi quem primeiro cencou provar isso: argumencou que a Terra deveria ser redonda. uma vez que sua sombra na Lua, durance um eclipse, era sempre arredondada. 
No texto da Figura 1, logo na segunda oração do primeiro parágrafo, observamos a seguinte afirmação: "Há relatos de concepções sobre nosso planeta e sobre o Universo que datam de 3 ou 4 mil anos atrás, mas somente no século VI a.C. (há 2.600 anos) iniciou-se uma investigação mais sistemática de fatos que conduzissem à percepção de que o nosso planeta é uma esfera". Tal afirmação nos traz algumas indagações: Por que não foram apresentados esses "relatos" no texto? A que povos pertencem esses "relatos"? Quem os classificou como relatos? Por que o texto trata como "investigação sistemática" apenas os apontamentos que se referem a registros de indivíduos europeus? O que o discurso presente neste texto pode representar para os estudantes?

O caderno de atividades propõe também que os alunos trabalhem o conteúdo indicado por meio de um trabalho em grupo e de forma autônoma. Trata-se da última atividade a ser desenvolvida com o conteúdo, conforme demonstrado na Figura 2:

Figura 2 - Atividade proposta na situação de aprendizagem 5

\section{PESQUISA EM GRUPO}

As representaçóes da Terra em diferentes épocas e culturas

Seguindo as indicaçóes do professor, pesquise sobre a origem e a forma da Terra, segundo:

a) lendas e mitos indígenas;

b) diferentes crenças religiosas;

c) algumas culturas da Antiguidade - os babilônios, os egípcios e os hindus.

Outros povos/culturas que tenham surgido nas discussóes anteriores também poderáo ser pesquisados.

Quando solicitado pelo professor, prepare cartazes com os resultados da pesquisa e os apresente em formato de seminário. Verifique a orientação do professor para a elaboração do seminário e para o tempo de cada apresentaçä́o.

Fonte: São Paulo (2015a, p. 62).

De acordo com a Figura 2, a proposta é de trabalho em grupo, no intervalo de uma aula, para tratar da referência a outros povos e outras culturas. A nosso ver, um tema de amplitude e complexidade fica à mercê da iniciativa dos estudantes. Desse modo, o currículo oficial desconsidera a importância 
do tratamento dado à diversidade étnico-racial e cultural, à medida que se submete ao risco de o conteúdo não receber o tratamento adequado e com a profundidade que carece.

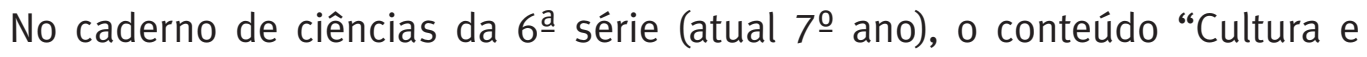
Constelações" é tratado na situação de aprendizagem 4, com o tema Céu e Cultura. Entre as atividades propostas na situação de aprendizagem, também encontramos o mesmo padrão de abordagem eurocêntrica dos conteúdos e a ausência de referências de origem africana. 0 texto de abertura da situação de aprendizagem indica o tom do tratamento da questão, conforme demonstrado na Figura 3.

Figura 3 - Texto referente à situação de aprendizagem 4

\section{SITUAÇĀO DE APRENDIZAGEM 4 CÉU E CULTURA}

\section{Leitura e análise de texto}

Uma leitura do mapa do céu

Há mais de 10 mil anos, o hometn, ao observar o céu, começou a perceher que as estrelas que surgiam no horizonte ao longo do ano nāo eram as mestnas. Assim, começou a mapeá-las. E foi desenhando mapas de estrelas que ele começou a associar o surgimento de algumas escrelas às estaçóes do ano. Assim, era possivel decidir pelo melhor momento do plantio.

Quando começou a mapear as estrelas, o homem imaginava algumas figuras formadas por elas e bacizava, assim, as constelaçóes. A de Órion, da qual as Trés Marias fazem parte, por exemplo, parecia com a figura de um caçador. $\mathrm{Na}$ prática, nem sempre é fácil associar às constelaçoóes as ima-

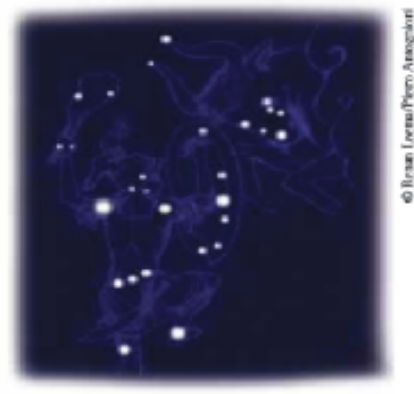

Constehefio de Ónion. gens de seus nomes no céu. No caso do Hemisfério Sul, temos mais uma dificuldade, pois as imagens aparecem inverridas no céu, de cabeça para baixo. Além das imagens, os gregos rambém criavam histórias sobre as imagens reproduzidas no céu. Essas histórias sáo conhecidas como mirologia.

Em cada constelaçtio, as estrelas sio designadas por letras do alfabeto grego (alfa, beta, gama, delta etc.), de acordo com o brilho que apresentam. Em praticamente todos os casos, a mais btilhaute é a Alfa, notne da. primeira letra do alfabeto grego; a segunda en brilho é a Beta; a ter ceira é a Gama, e assim por diante. Algumas estrelas do céu possuem nomes próprios.

Quando vistas da Terra, as estrelas que formam uma constelaçăo parecetn próximas entre si. $\mathrm{Na}$

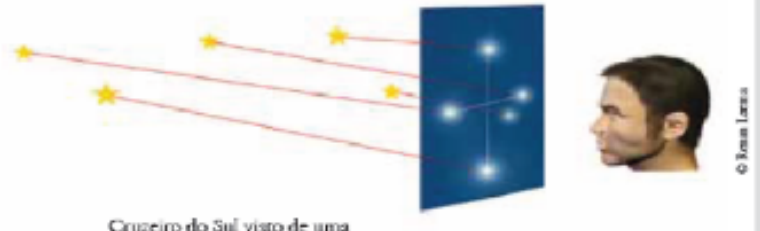
Cruzeiro do Sul visto de uns ecreba divance da Terre

Cruneiro do Sal visto da Terra.

arofun muico distantes utmas das outras. Setia interessante imaginat como seria a disposiçáo dessas estrelas se vistas de uma outra estrela. Na figura acima temos um exemplo de como uma constelaçío, o Cruzeiro do Sul, seria observada da Terra e de uma estrela distante da Terra. 
O tema da situação de aprendizagem para ser desenvolvido com os alunos do $7^{0}$ ano denomina-se Céu e Cultura (Figura 3), o que sugeriria uma ótima oportunidade para se abordar a percepção do céu e suas constelações por diferentes culturas, povos e nações. No entanto, o texto cita apenas o povo grego como criador das "imagens" e "histórias das imagens" observadas no céu.

Como sugestão de atividade a ser desenvolvida pelos estudantes, o caderno de atividades apresenta o texto "O céu dos índios tembés”, de acordo com a Figura 4, como forma de tratar a relação da etnia com as constelações e as estações de chuva e seca.

Figura 4 - Texto complementar referente à situação de aprendizagem 4

\section{Leitura e análise de texto}

\section{O céu dos índios tembés}

Os índios rembés, do sul do Pará, também associaram conjuntos de estrelas a imagens, em sua maioria de animais de seu cotidiano, como a seriema, a ema, o beija-flor, a anta etc. Para eles, o nascimento de algumas constelaçóes no céu no ocaso do Sol indica estaçóes de chuva ou de seca. As constelaçốes da Ema (Wiranu) e da Seriema (Azim), por exemplo, marcam a estaçáo da seca, época de colheita. A constelação do Queixo da Anta (Tapi'i Hazywer), surgindo no céu ao anoitecer no lado leste, marca o início da estaçáo da chuva.

Para obter informaçōes e imagens de constelaçóes de

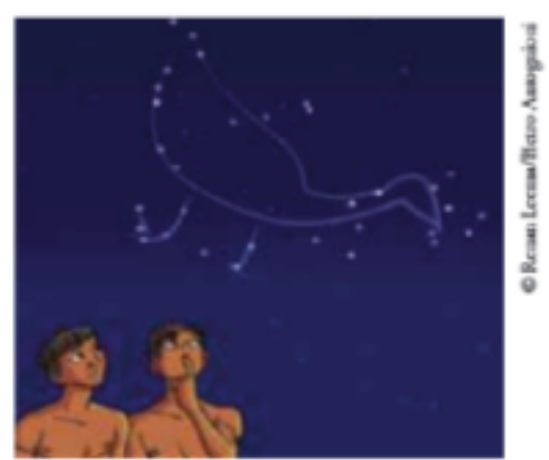

Formaça de constelaçoes pelos indios tembes. outras culturas, acesse o site: <http://www.telescopiosnaescola.pro.br/indigenas.pdfs (acesso em: 22 ago. 2013).

Conforme a Figura 4, o encaminhamento da atividade com o texto apresenta apenas uma única questão, pedindo que o estudante responda o porquê das diferentes imagens vistas pelos gregos e pelos indígenas da etnia Tembé, se as estrelas observadas são as mesmas.

O tema "Céu e Cultura" continua sendo abordado em pelo menos outras duas situações de aprendizagem ao longo do $1^{\underline{0}}$ bimestre. Em uma das atividades, há breve referência ao mito da criação do homem dos indígenas da etnia Kaingang. No que diz respeito às referências de bases 
africanas, como na atividade analisada anteriormente, elas estão ausentes. Assim, temos, no material observado, a completa omissão da produção do conhecimento astronômico de base africana e o conhecimento de base indígena apresentado exclusivamente em seu aspecto mítico e de modo superficial.

Ao longo deste texto, apontamos alguns estudos que fazem referências à tradução de 14 manuscritos de Timbuktu, na Universidade de Sankore (local de desenvolvimento de conhecimentos astronômicos, como a visão heliocêntrica do sistema solar e a aplicação de cálculos matemáticos complexos para constituir diagramas de planetas e órbitas); à astronomia egípcia; ao sítio astronômico de Namoratunga II, no Quênia e ao complexo conhecimento astronômico do povo Dogon, do Mali. Portanto, há muito que ser considerado e reconhecido sobre o conhecimento astronômico de povos africanos e que poderiam fazer parte do conteúdo programático do currículo oficial.

Entendemos que professores e professoras, fazendo uso de sua autonomia didática e reconhecendo a diversidade étnico-racial como princípio de ensino, podem realizar intervenções nas atividades propostas nessas situações de aprendizagem, de modo a garantir a inclusão, a denúncia das ausências e a visibilidade de conhecimentos historicamente ignorados.

\section{CONSIDERAÇÕES FINAIS}

A Lei $10.639 / 03$ e suas diretrizes buscam a inclusão de referências históricas que estão ausentes e têm sido sistematicamente negadas nas práticas curriculares, mesmo após 14 anos de sua promulgação. No caso da educação pública estadual paulista, observamos que o material pedagógico, disponibilizado pela Secretaria Estadual de Educação dos anos finais do ensino fundamental na disciplina de ciências, desconsidera conteúdos referentes ao ensino da história e da cultura afro-brasileira e africana.

Em outras palavras, o currículo oficial do estado de São Paulo descumpre as determinações da LDBEN 9.394/96 em seu Artigo 26A - a Lei 10.639/03 e suas diretrizes. Essa postura evidencia um posicionamento político que ignora categorias importantes na formação dos estudantes que atende. Os documentos oficiais, assim como o material pedagógico disponibilizado, não contemplam conteúdos que podem contribuir para a formação capaz de mobilizar educandos para o reconhecimento das diferentes culturas na produção de conhecimento e constituição das sociedades. 
Nessas condições, o tratamento das prescrições legais fica à mercê da sensibilidade individual e formação dos docentes, uma vez que não observamos, por parte das agências estaduais, atuação no sentido de promover o debate e o incentivo à prática, tendo a diversidade étnico-racial e cultural como instrumento.

No interior das escolas públicas, entre as razões da omissão da temática na prática docente, podemos identificar: a naturalização do currículo eurocêntrico; a falta de informação sobre o conteúdo e a perspectiva de abordagem proposta pela legislação; o desconhecimento das culturas africanas, afrobrasileiras e indígenas; a prática pedagógica apoiada em cartilhas; a carência nos processos de formação inicial e continuada e a falta de orientações e debates nos horários de estudo em conjunto.

Essa omissão generalizada relaciona-se de modo mais profundo com mecanismos sutis de manutenção de padrões ideológicos. Os docentes que atuam na educação básica não têm recebido formação no sentido de problematizarem a questão curricular, a fim de atuarem no rompimento da visão eurocêntrica na produção do conhecimento e pensamento ocidental. A falta de informação e de formação na temática da diversidade étnico-racial e cultural são fatores que limitam, consideravelmente, a atuação docente. Essa perspectiva hegemônica posiciona o professor em uma postura resignada, diante da problematização das questões relativas à trajetória dos povos africanos na gênese do conhecimento nas diversas áreas de atividade humana.

A necessidade que se faz urgente é a denúncia da ausência no currículo oficial das escolas públicas paulistas, buscando ainda evidenciar as possibilidades de inclusão desses conteúdos e saberes em situações de aprendizagem, inclusive no ensino de ciências. Um trabalho com abordagem positiva da trajetória de povos africanos cria condições de reconhecimento de suas histórias, epistemologias e práticas socioculturais, formando, assim, as bases de uma educação capaz de contribuir com processos de construção identitária na autoaceitação, no reconhecimento das diferenças e no combate ao racismo.

O educador, na condição de agente de mudanças, lançando-seao enfrentamento das demandas que uma escola pluriétnica impõe à prática docente, necessita de apoio em seus processos de formação inicial e continuada, na abordagem da Lei 10.639/03 e de todo o conjunto de dispositivos legais que primam pela sua implantação. A atuação docente precisa dotar-se de capacidade de respostas, tanto à engenharia de controle curricular exercido pelas agências 
estaduais quanto aos grupos excluídos pela tradição seletiva do currículo oficial, promovendo práticas curriculares que rompam com a lógica da colonização epistemológica. 


\section{Scientific and Technological Knowledge of African Peoples: Strategy of Resistance to the Selective Tradition in Science Education}

Abstract: This article examines possibilities of including African and AfroBrazilian history and culture in science education, in compliance with the Law 10.639 / 03. It advocates the inclusion of ethnic-racial and cultural diversity, based on historical references to the scientific knowledge of African peoples. We analyze the contents proposed in the official curriculum issued by the Education Department of the State of São Paulo (SEE / SP), specifically for the 7 th grade of primary education. We propose a reflection on the pedagogical action of those involved in school education as an instrument that can produce significations in stances towards demands related to fighting racially based prejudice and discrimination.

Keywords: Anti-racist education. African science and technology. Curriculum. Science teaching. 


\section{Conocimiento científico y tecnológico de los pueblos africanos: estrategia de resistencia a la tradición selectiva en la enseñanza de ciencias}

Resumen: El presente artículo examina las posibilidades de inclusión de la historia y de las culturas africanas y afrobrasileñas en la enseñanza de ciencias, en atención a la ley brasileña 10.639/03, defendiendo la inserción de la diversidad étnico-racial y cultural a partir del extracto histórico referente al conocimiento científico de los pueblos africanos. El análisis se realiza a partir de los contenidos propuestos en el currículo escolar oficial de la Secretaría de Educación del Estado de São Paulo (SEE/SP), en concreto los correspondientes al séptimo año de la enseñanza primaria. La propuesta es reflexionar sobre la actuación pedagógica de los implicados en la educación escolar, como instrumento capaz de originar significaciones en el posicionamiento frente a las demandas relativas al enfrentamiento del prejuicio y de la discriminación con fundamento racial.

Palabras clave: Educación antirracista. Ciencia y tecnología africana. Currículo. Enseñanza de ciencias. 


\section{REFERÊNCIAS}

ADELEKE, Tunde. The Case against Afrocentrism. Jackson: University Press of Mississippi, 2009.

APPLE, Michael Whitman. Educação e Poder. Tradução João Menelau Paraskeva. Porto: Porto Editora, 2001.

ASANTE, Molefi Kete. International/intercultural relations. In: ASANTE, Molefi Kete; VANDI, Abdulai S. (Org.). Contemporary black thought. Beverly Hills: Sage, 1980.

ASSIS, Mariza de Paula. A questão racial na formação de professores na perspectiva dos docentes da FFP. 2006. 187 f. Dissertação (Mestrado em Política Social) - Universidade Federal Fluminense, Rio de Janeiro, 2006.

BRASIL. Presidência da República. Lei n. 10.639, de 9 de janeiro de 2003. Altera a Lei n. 9.394, de 20 de dezembro de 1996, que estabelece as diretrizes e bases da educação nacional, para incluir no currículo oficial da Rede de Ensino a obrigatoriedade da temática "História e Cultura Afro-Brasileira”, e dá outras providências. Brasília, 2003. Disponível em: 〈http://www.planalto.gov. br/ccivil_03/leis/2003/L10.639.htm>. Acesso em: 12 jan. 2016.

- Parecer 03/2004 do Conselho Pleno do Conselho Nacional de Educação. Brasília: MEC, 2004.

CANDAU, Vera Maria Ferrão. Diferenças culturais, cotidiano escolar e práticas pedagógicas. Currículo sem Fronteiras, v. 11, n. 2, p. 240-255, jul./dez. 2011.

COSTA NETO, Antonio Gomes da. A diversidade étnico-racial como novo princípio da LDB. Revista Educação Pública, 2013. Disponível em: 〈http:// www.educacaopublica.rj.gov.br/biblioteca/educacao/0385.htmlı. Acesso em: 15 jan. 2016.

DIOP, Cheikh Anta. Nations Nègres et Culture. Paris: Editions Présence Africaine, 1954.

Antériorité des Civilisations Nègres: mythes ou vérité historique? Paris: Editions Présence Africaine, 1967.

FANON, Frantz. Pele negra, máscaras brancas. Tradução Renato da Silveira. Salvador: Edufba, 2008. 
FARRINGTON, Benjamin. A ciência grega e o que significa para nós. São Paulo: Ibrasa ,1961.

FERNANDES, Florestan. A integração do negro na sociedade de classes. 3. ed. São Paulo: Ática, 1978.

FONSECA, Dagoberto José. A história, o africano e o afro-brasileiro. In: Caderno de formação: formação de professores didática dos conteúdos. Universidade Estadual Paulista. Pró-Reitoria de Graduação, Universidade Virtual do Estado de São Paulo. São Paulo: Cultura Acadêmica, 2012. v. 9.

HALL, Stuart. Da Diáspora: identidades e mediações culturais. In: SOVIK, Liv (Org.). Tradução Adelaine La Guardiã Resende. Belo Horizonte: Editora UFMG, Brasília: Representações da Unesco no Brasil, 2003.

HOWE, Stephen. Afrocentrism Mythical Pasts and Imagined Homes. Nova York: Verso, 1998.

JAMES, George G. M. Stolen Legacy, Greek Philosophy is Stolen Egyptian Philosophy. Trenton, New Jersey: África World Press, 1992.

KI-ZERBO, Joseph. História da África Negra II. 1972. Disponível em: 〈http:// www.angolapress-angop.ao/diadeafrica-historia.asp/s. Acesso em: 20 jan. 2016.

LEFKOWITZ, Mary. Not Out Of Africa How Afrocentrism Became an Excuse to Teach Myth as History. Nova York: New Republic Books, 1997.

MACHADO, Carlos Eduardo Dias. Ciência, tecnologia e inovação africana e afrodescendente. Brasília: Fundação Cultural Palmares, 2014.

MOORE, Carlos Wedderburn. 0 racismo através da história: da antiguidade à modernidade. 2007. Disponível em: 〈http://www.ipeafro.org.br/10_afro_em_ foco/Moore_Racismo_atraves_da_historia.pdf〉. Acesso em: 15 ago. 2015.

. Novas bases para o ensino da história da África no Brasil. In: BRASIL - MEC/SECAD. Educação anti-racista: caminhos abertos pela Lei Federal n. 10.639/03. Brasília: MEC/Secad, 2005. p. 133-166.

MUNANGA, Kabengele. Estratégias de combate à discriminação racial. São Paulo: Editora da Universidade de São Paulo-Edusp/Estação Ciência, 1996.

NASCIMENTO, Elisa Larkin. O sortilégio da cor: identidade, raça e gênero no Brasil. São Paulo: Selo Negro, 2003. 
. O tempo dos povos africanos. Suplemento didático da linha do tempo dos povos africanos. Ipeafro, Secad/MEC, Unesco, 2007. Disponível em: 〈http://ipeafro.org.br/acervo-digital/leituras/publicacoes-do-ipeafro/ suplemento-didatico/>. Acesso em: 11 jan. 2016.

. Sankofa: significado e intenções. In: NASCIMENTO, Elisa Larkin (Org). Sankofa: matrizes africanas da cultura brasileira. Rio de Janeiro: Eduerj, 1996. v. 1.

(Org.). Sankofa: resgate da cultura afro-brasileira. Rio de Janeiro: Secretaria Extraordinária de Defesa e Promoção das Populações AfroBrasileiras (Seafro), 1994. v. 1

OBENGA, Théophile. Le sens de lutte contre l'africanisme eurocentriste. Paris: L'Harmattan/Khepera, 2001.

QUIJANO, Aníbal. Colonialidade do poder, eurocentrismo e América Latina. In: LANDER, EDGARDO (Org.). A colonialidade do saber: eurocentrismo e ciências sociais. Perspectivas latino-americanas. Buenos Aires: Consejo Latinoamericano de Ciências Sociales, 2005.

SÃO PAULO. Material de apoio ao currículo do Estado de São Paulo. Caderno do aluno 2014_2017. Ciências da Natureza - Ciências. Ensino Fundamental Anos Finais 5a série/6ํano, v. 2, nova edição. São Paulo: SEE, 2015 a.

- Material de apoio ao currículo do Estado de São Paulo. Caderno do aluno 2014_2017. Ciências da Natureza - Ciências. Ensino Fundamental - Anos Finais 6므 série/7ํa ano, v. 2, nova edição. São Paulo: SEE, 2015b.

Proposta Curricular do Estado de São Paulo: Ciências. São Paulo: SEE, 2008.

SEGATO, Rita Laura. Raça é signo. Série Antropologia, Universidade de Brasília, n. 372, p. 3-16, 2005. Disponível em: 〈http://vsites.unb.br/ics/dan/ Serie372empdf.pdf〉. Acesso em: 5 nov. 2014.

SILVA, Maria José Albuquerque da; BRANDIN, Maria Rejane Lima. Multiculturalismo e educação: em defesa da diversidade cultural. Diversa, ano I, n. 1, p. 51-66, jan./jun. 2008.

SOUZA, Eliane Almeida de. A lei 10.639/03 na formação de professores e o pertencimento étnico-racial em escolas públicas de Porto Alegre. 2009. 140 f. Dissertação (Mestrado em Educação) - Programa de Pós-Graduação em 
Educação, Faculdade de Educação, Universidade Federal do Rio Grande do Sul, Porto Alegre, 2009.

TAYLOR, Charles. Lapolítica del reconocimiento.In: Elmulticulturalismo y La política del reconocimiento. Tradução Mónica Utrilla de Neira. México: Fondo de Cultura Económica, 1993.

VAN SERTIMA, Ivan (Org.). Black in science, ancient and modern. New Brunswick (EUA): Oxford (RU): Transaction Books, 1983.

WALKER, Clarence E. We Cant Go Home Again An Argument about Afrocentrism. Nova York: Oxford University Press, 2001.

WILLIAMS, Raymond. Cultura e sociedade. São Paulo: Companhia Editora Nacional, 1978.

\section{SOBRE OS AUTORES}

Marlene Oliveira de Brito é mestre em Docência para a Educação Básica pela Universidade Estadual Paulista Júlio de Mesquita Filho (Unesp), campus de Bauru. Atua como pesquisadora e professora efetiva do ensino fundamental anos iniciais da rede estadual de ensino de São Paulo.

E-mail: azeviche2@gmail.com

Vitor Machado é doutor em Educação pela Unicamp. Atua como docente assistente doutor do Departamento de Educação e do Programa de PósGraduação em Docência para a Educação Básica da Faculdade de Ciências da Unesp, campus de Bauru.

E-mail:vitor@fc.unesp.br

Recebido em: abril de 2017

Aprovado em: junho de 2017 